\title{
Non-coding sequence retrieval system for comparative genomic analysis of gene regulatory elements Sung Tae Doh ${ }^{1}$, Yunyu Zhang ${ }^{2}$, Matthew H Temple ${ }^{2}$ and Li Cai*1
} \author{
Institute, 44 Binney Street, Boston, MA 02115, USA \\ Email: Sung Tae Doh - sungtae@rci.rutgers.edu; Yunyu Zhang - yunyu_zhang@dfci.harvard.edu; \\ Matthew H Temple - mht@research.dfci.harvard.edu; Li Cai* - lcai@rutgers.edu \\ * Corresponding author
}

Address: ${ }^{1}$ Biomedical Engineering Department, Rutgers University, 599 Taylor Road, Piscataway, NJ 08854, USA and ${ }^{2}$ Dana-Farber Cancer

Published: I5 March 2007

BMC Bioinformatics 2007, 8:94 doi:10.1/86/147|-2105-8-94
Received: 14 September 2006

Accepted: 15 March 2007

This article is available from: http://www.biomedcentral.com/I47/-2/05/8/94

(C) 2007 Doh et al; licensee BioMed Central Ltd.

This is an Open Access article distributed under the terms of the Creative Commons Attribution License (http://creativecommons.org/licenses/by/2.0), which permits unrestricted use, distribution, and reproduction in any medium, provided the original work is properly cited.

\begin{abstract}
Background: Completion of the human genome sequence along with other species allows for greater understanding of the biochemical mechanisms and processes that govern healthy as well as diseased states. The large size of the genome sequences has made them difficult to study using traditional methods. There are many studies focusing on the protein coding sequences, however, not much is known about the function of non-coding regions of the genome. It has been demonstrated that parts of the non-coding region play a critical role as gene regulatory elements. Enhancers that regulate transcription processes have been found in intergenic regions. Furthermore, it is observed that regulatory elements found in non-coding regions are highly conserved across different species. However, the analysis of these regulatory elements is not as straightforward as it may first seem. The development of a centralized resource that allows for the quick and easy retrieval of non-coding sequences from multiple species and is capable of handing multi-gene queries is critical for the analysis of non-coding sequences. Here we describe the development of a web-based non-coding sequence retrieval system.
\end{abstract}

Results: This paper presents a Non-Coding Sequences Retrieval System (NCSRS). The NCSRS is a web-based bioinformatics tool that performs fast and convenient retrieval of non-coding and coding sequences from multiple species related to a specific gene or set of genes. This tool has compiled resources from multiple sources into one easy to use and convenient web based interface. With no software installation necessary, the user needs only internet access to use this tool.

Conclusion: The unique features of this tool will be very helpful for those studying gene regulatory elements that exist in non-coding regions. The web based application can be accessed on the internet at: http://cell.rutgers.edu/ncsrs/.

\section{Background}

While annotation efforts and gene prediction methods have begun the process of identifying protein-coding genes, robust high-throughput methods for detecting functional non-protein coding elements remain elusive [1]. Only about 2 percent of the human or mouse genomes consist of DNA sequences that are protein-coding regions $[2,3]$. The remaining vast majority of the 
genome consists of non-coding sequences (NCS). It has been shown that gene regulatory elements (GREs) reside in the NCS $[4,5]$. GREs have been broadly placed into two major functional groups: promoters and enhancers. Promoters are sequences that direct the precise locations of transcription start sites. Enhancers, repressor, and silencers, etc. are sequences that bind gene regulatory proteins and influence the transcription activity of a gene. GREs can be located upstream, downstream, or even internal to the target gene. GREs, therefore, act as switches to turn gene expression on or off and as modulators to increase or decrease expression. Traditionally, NCS have not received as much attention from investigators as protein coding sequences and GREs are generally poorly defined, mostly as only sequence motifs. Research is now focusing increasingly on non-coding sequences and specifically the search for NCS with regulatory functions. Identifying functional NCS and understanding their mechanism of operation will shed new insights into the understanding of the regulatory functions of transcription, DNA replication, chromosome pairing, and chromosome condensation $[2,6]$. In order for the full understanding and eventual control of biological function, not only must the genes involved in a particular function be identified but the regulatory elements that trigger and control the biochemical pathways that determine each gene's expression must also be well understood. However, searching for functional GREs within the NCS that comprise roughly $98 \%$ of the genome is not a simple task. The size and scope of this search brings with it many intellectual and experimental challenges that span computational biology and comparative functional genomics [7].

There are two commonly used methods for identification of functional GREs. The first uses gene expression analysis and the second uses comparative genomics. DNA microarray gene expression profiling is capable of evaluating thousands of genes across various experimental conditions. Bioinformatics approaches are used to cluster genes that show similar patterns of expression. Once genes with similar patterns of expression are identified, they are searched within their upstream sequences to identify overrepresented or conserved sequence motifs [8,9]. Sequence alignment algorithms employed by the comparative genomic methods are powerful in identifying conserved sequences in non-coding regions located in and around genes with the same function, known as homologous genes, from diverse species. Homologous genes usually have the same function and may also have similar regulatory elements that control this function. Functional regions (which consist of protein coding regions along with regulatory regions) experience selective pressure against change and therefore have a higher level of sequence conservation across a wide range of species than non-functional regions. Ideally, selective pressures would allow for non-functional sequences to diverge due to evolutionary drift while leaving functional regions with high similarity [1,10-17]. DNA sequence comparison of the human and mouse orthologous genes have indicated that conserved NCS are enriched significantly in regulatory sequence regions $[4,18,19]$. Subsequent to the identification of putative regulatory elements by sequence comparison, the confirmation of biological function will depend upon experimental assays. Transcriptional regulatory regions in genes from humans, mouse, Fugu fish, Caenorhabditis elegans, Drosophila, and yeast [5,6,20-24] have been identified. The power of comparative genomics analysis is enhanced significantly when genomic sequences are available from a number of related species that have diverged sufficiently. This reduces the chances of conservation among non-functional elements. By comparing multiple genomes, it can help to determine which conserved elements are more likely to be functional $[5,21,25,26]$.

Whether the focus is on genes with similar expression patterns or those expected to have the same function, both analysis methods require the retrieval of NCS for the identification of functional sequence elements. Currently, the process of retrieving these sequences is performed manually from a wide range of sources. No efficient method is available for retrieving NCS quickly and systematically at a single source. To facilitate the analysis of NCS for functional regulatory elements, we present here a web-based non-coding sequences retrieval system (NCSRS) that performs the automated retrieval of non-coding sequences among genomes of different species. A previously developed application for retrieving NCS, called Retrieval of Regulative Regions (RRE) [27] parses annotation and homology data from NCBI to identify NCS. This parser requires local installation but also requires a local copy of desired genomes and annotation files. A web based application is also available but only a few genomes are currently available and RRE utilizes annotation data from only NCBI. The NCSRS requires no installation or local management of genome sequence databases and utilizes annotation information from both NCBI and Ensembl. Currently, NCSRS has 15 genomes (containing over 85 Gigabyte of DNA sequence data) with sufficient annotations available for NCS retrieval.

\section{Implementation}

\section{Annotation and sequence information}

There are two major groups currently working on genome annotation. Data from these two sources serve as the source of the annotation information that comprises the core for this tool. These include NCBI RefSeq [28] and Ensembl [29]. RefSeq is a partially manually curated annotation database which includes information based on predicted mRNAs and proteins. The genes with manu- 
ally curated mRNA information are labelled with the "NM" prefix while the genes based on predicted mRNA information are labelled with an "XM" prefix. Ensembl's gene predictions are automated but all predictions are based on experimental mRNA evidence. The Ensembl annotation system marks predicted genes as either known or novel based on the level of experimental support and information from other annotation sources. The number of genes annotated by Ensembl and Refseq are listed in table 1 and 2. Table 3 shows the number of genes annotated in Refseq are also included in the Ensembl system along with the percentage of overlap between the two with respect to the total number of annotated genes in the Ensembl system. The pros and cons of each will not be discussed here but rather it is emphasized that this tool offers users the freedom to choose.

The RefSeq annotation data (RefGene.txt, RefLink.txt) is obtained for each genome from the Human Genome Browser at UCSC [30] ftp site[31] as are some of the genome sequences. The remaining genome sequences along with the Ensembl data (gene, transcript, and structure files for each genome) are obtained from Ensembl's ftp site[32]. Both sets of gene annotations are downloaded and then processed to serve as the basis for building a genome map that contains the location of each gene and all its exons. Ensembl includes 5' and 3' UTR's along with coding exons when counting the total number of exons. 5' and 3' UTR's are also listed on their website as exons and are included in the downloadable annotation files as exons. Therefore, following this convention, $5^{\prime}$ and 3' UTR's have also been included in the list of exons by NCSRS. In those cases where multiple transcripts are available, the transcript with the greatest number of exons is used. Because not all the transcript information is used to define sequences in the intron region there is the potential that an exon from an unused transcript variant may not be shared with the utilized transcript. In this case, the unshared exon would be "hidden" from the annotation and returned as part of the non-coding sequence. However this is not relevant in the majority of cases as "hidden" exons are not the norm. Furthermore, this is limited to only the intragenic region and would not affect the up and down stream sequences.

In this paper non-coding regions refer to all sequences that are not exons. The definition of exons will follow the convention used by Ensembl of defining exons as the set of 5' UTRs, coding exons, and 3' UTRs. Ensembl includes $5^{\prime}$ and $3^{\prime}$ UTRs in their total exon counts both on their website and in the downloadable annotation files [29,33]. While it is arguable that UTR's can be considered non-coding regions, for the sake of consistency and clarity, the convention followed by Ensembl is maintained.

\section{Homology prediction}

The RefSeq annotation information, called Homologene [34], is the basis for the homologous gene prediction system. This system is implemented in the NCSRS by using the single "homologene.data" file [35] for gene annotation information from RefSeq. This file is a list of the sets of homologous genes for all genes annotated by RefSeq. Ensembl has its own homology prediction method and its output is organized in a set of multiple files. The Ensembl annotation information is the basis for its homologous gene prediction and therefore when using Ensembl's annotation information, Ensembl's homology prediction results are used. Simple analysis of the data generated by the two homology prediction methods shows that both systems have good coverage for those genomes most commonly used for research (see Table 2). As the annotations improve, the results of the predictions will also improve in accuracy and percent coverage.

\section{Input}

The user's input of the desired search options on the user interface (Figure 1) determines the work-flow path (Figure 2 ). The search options include the input type, genome or genomes from which sequences will be extracted, range of sequence extension, exon masking, and output format. The user inputs the individual gene or set of genes of interest. The input can be either the Entrez gene id or HUGO gene symbol (default) but must be the same for all the genes of a given search. The non-coding sequences from a specific species can be returned by selecting the desired species from a pull down menu or from all species with a known orthologous gene, by activating the "pull all ortholog sequences" option according to the homologene database.

\section{Mapping}

Using the annotation information all annotated genes are sorted based on chromosomal position. Then the start and stop locations for all coding regions are identified. By identifying the coding regions we can also determine the locations of the non-coding regions using genomic position information, or mapping, of a specified gene and its flanking genes. The non-coding sequences are identified simply as those located between the adjacent identified exons. The information for each gene's non-coding region is then written to a new set of files that are used by the NCSRS. This non-coding region annotation serves as the basis for the locations of the end points for each intergenic and intragenic region.

\section{Retrieval of non-coding sequences}

Using the locations of non-coding regions the appropriate genomic sequence is identified. The genome sequence file is read and the specified sequences are extracted and copied to a new file according to the appropriate position 
Table I: Statistics of gene annotation for ENSEMBL and NCBI.

\begin{tabular}{ccccccc}
\hline \multicolumn{2}{l}{ ENSEMBL - as of 12/06/06 } & & & \\
\hline Organism & Assembly & Genebuild Date & Version & Known & Novel & $\begin{array}{c}\text { Total } \\
\text { Predictions }\end{array}$ \\
Human & NCBI 36 & Aug 2006 & $41.36 \mathrm{c}$ & 22205 & 6918 & 1019 \\
Mouse & NCBI m36 & Apr 2006 & $41.36 \mathrm{~b}$ & 21839 & 2599 & 71259 \\
Chicken & WASHUC I & Dec 2005 & $41.1 \mathrm{p}$ & 5123 & 5417 & 76146 \\
\hline
\end{tabular}

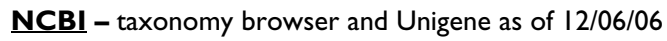

\begin{tabular}{ccccc}
\hline Organism & Assembly & GenBank Date & UniGene Build & Entrez Genes \\
human & NCBI 36 & Oct 2006 & 197 & 38597 \\
mouse & NCBI m36 & Oct 2006 & 159 & 60745 \\
chicken & WASHUC I & Aug 2006 & 31 & 24313 \\
\hline
\end{tabular}

Known - genes that have species-specific protein sequences already available in the public sequence databases. Novel - genes that could not be mapped with confidence to existing entries. Total Predictions - the number of 'known', 'novel' and 'pseudogenes' predicted by the Ensembl analysis and annotation pipeline.

Entrez Genes - number of genes defined by sequence and/or located in the NCBI Map Viewer. Total Unigene Clusters - the number of nonredundant sets of gene-oriented clusters automatically partitioned by UniGene.

information. The NCSRS by default outputs the non-coding sequence of the specified gene starting from the end of its adjacent gene and ending with the start of the other adjacent gene (as marked with 2 "X"s in Figure 1). Unless specified otherwise the NCSRS also outputs the intergenic sequences, exons and introns. The boundaries for the flanking regions can be arbitrarily set by specifying the extension length in the options, e.g., with a specified extension length of 5000 bp. Then, 5000 bp up- and down-stream of the queried gene will be included in the extraction irrespective of the location of neighbouring genes. Each sequence has a pair of associated files: FASTA format sequence file with file extension ".fa" and EXON definition file with file extension ".exon", both with file names generated using the UCSC annotation format. The ".fa" file contains the sequence in FASTA format. The first line of the ".exon" file defines the span of the coding region. The first line also contains other information such

Table 2: Statistics of homology prediction for human, mouse, and chicken

\begin{tabular}{|c|c|c|c|c|}
\hline \multirow[t]{2}{*}{ Ensembl (mart 4I) } & & \multicolumn{3}{|c|}{ Baseline Species for Homology Search } \\
\hline & & Human & Mouse & Chicken \\
\hline \multirow{3}{*}{$\begin{array}{c}\text { Species of Homologous } \\
\text { Genes }\end{array}$} & Human & - & $13049 / 46.7 \%$ & $9839 / 50.7 \%$ \\
\hline & Mouse & |2036/38.6\% & - & $11698 / 60.3 \%$ \\
\hline & Chicken & I I $773 / 37.7 \%$ & $12187 / 43.6 \%$ & - \\
\hline \multicolumn{2}{|c|}{ Total number of genes } & 31206 & 27964 & 19399 \\
\hline \multicolumn{2}{|c|}{ Homologene (release 53) } & \multicolumn{3}{|c|}{ Baseline Species for Homology Search } \\
\hline & & Human & Mouse & Chicken \\
\hline \multirow{3}{*}{$\begin{array}{c}\text { Species of Homologous } \\
\text { Genes }\end{array}$} & Human & - & $16325 / 73.0 \%$ & $10498 / 84.0 \%$ \\
\hline & Mouse & $16325 / 41.2 \%$ & - & $10299 / 83.3 \%$ \\
\hline & Chicken & $10498 / 26.5 \%$ & $10299 / 46.6 \%$ & - \\
\hline \multicolumn{2}{|c|}{ Total number of genes } & 39605 & 22364 & 12500 \\
\hline
\end{tabular}

The homolog data table files for each of the baseline species were queried to find the total number of genes along with the number of homologous genes that are present in another given species' genome. Similarly the homologene.data file was used to generate the homologene statistics. Shown are the number of homologs and the percentage of coverage (the number of genes that have homologs in a particular species' genome divided by the total number of genes for the baseline species.) 
Table 3: Analysis of known and predicted genes for chicken, rat, mouse, and human from Ensembl Mart v.4I

\begin{tabular}{|c|c|c|c|c|c|c|}
\hline \multirow[t]{2}{*}{ Species } & \multicolumn{3}{|c|}{ NM (known) } & \multicolumn{3}{|c|}{ XM (predicted) } \\
\hline & $\begin{array}{l}\text { Refseq known } \\
\text { to Ensembl }\end{array}$ & Ensembl & Percentage & $\begin{array}{l}\text { Refseq known } \\
\text { to Ensembl }\end{array}$ & Ensembl & Percentage \\
\hline Chicken & 2726 & 24939 & $10.93 \%$ & 1 & 24910 & $0.00 \%$ \\
\hline Rat & 9119 & 37825 & $24.11 \%$ & 9731 & 38778 & $25.09 \%$ \\
\hline Mouse & 21336 & 36898 & $57.82 \%$ & 16931 & 46566 & $36.36 \%$ \\
\hline \multirow[t]{2}{*}{ Human } & 29836 & 62076 & $48.06 \%$ & 9849 & 63575 & $15.49 \%$ \\
\hline & \multicolumn{3}{|c|}{ TOTAL } & & & \\
\hline Species & $\begin{array}{l}\text { Refseq known } \\
\text { to Ensembl }\end{array}$ & Ensembl & Percentage & & & \\
\hline Chicken & 2727 & 49849 & $5.47 \%$ & & & \\
\hline Rat & 18850 & 76603 & $24.61 \%$ & & & \\
\hline Mouse & 38267 & 83464 & $45.85 \%$ & & & \\
\hline Human & 39685 & $|2565|$ & $31.58 \%$ & & & \\
\hline
\end{tabular}

as the name of the gene the chromosome the gene is located and the chromosomal position of the extracted NCS. The following lines list pairs of locations which represent the start and end of all the exons. These locations are relative to the start of the sequence in the ".fa" file. The set of sequences and exon annotation files are packaged as a compressed file that is available for download through a link on the results webpage (Figure 3 ). The result webpage also has a table of the gene or genes returned, for each genome that is currently available, along with a link to the results for each genes query of NCBI's entrez gene site [36], a gene map view from UCSC's genome bioinformatics website [37], and further gene information at Ensembl's website [38].

\section{Updating}

Both annotation systems, Refseq and Ensembl, are works in progress and with subsequent releases, the annotations will improve in scope and accuracy. New genome assemblies will also continue to be released for new and existing genomes. As the sequence and annotation information which serve as the basis for this system are refined, the sequences generated by this system will improve. Therefore, it is critical that the genomes and annotation information are kept up to date. The NCSRS will be updated automatically on a weekly basis to ensure that the most recent information is always available.

\section{Hardware and software}

The NCSRS uses a single computer that acts as both the server and database. There is also a developmental computer which is used for updating, designing new applications, and troubleshooting. The main server uses Dual
Intel ${ }^{\oplus}$ Xeon $^{\circledast}$ Processors at $3.0 \mathrm{GHz}$, with 4 Gb RAM and 500 GB Hard Disk space and runs apache 2.2 as its web server. The scripts and programs used by NCSRS for building and accessing the databases are written predominantly in PHP and Perl.

\section{Results}

We have developed a web-based sequence retrieval system that quickly and easily extracts non-coding sequences associated with a specific user defined gene set from a single and/or multiple genomes. The NCSRS efficiently delivers non-coding sequences for specified genes or gene sets using a user-friendly interface from a single site. This system eliminates the need to manually sift though genome sequences and look for annotation information from multiple sources. This will help eliminate human errors as well as increase throughput for those investigating gene regulatory elements. The system also allows the user to specify the gene or set of genes for retrieval while maintaining a simple user interface, enabling the user to apply their expert knowledge without having to spend a lot of time learning how to use the system. Another option that is important for those seeking to elucidate functional NCS is masking. Repetitive sequence elements found in the genome can cause sequence alignment algorithms to predict conserved elements that do not have gene regulatory function. For this reason, there is an available option to mask sequences as repeated sequences to allow for alignment algorithms to ignore repeated sequences [1].

This system has great flexibility in its potential applications. An important and unique feature is that if the user intends to apply this tool to a comparative genomics 


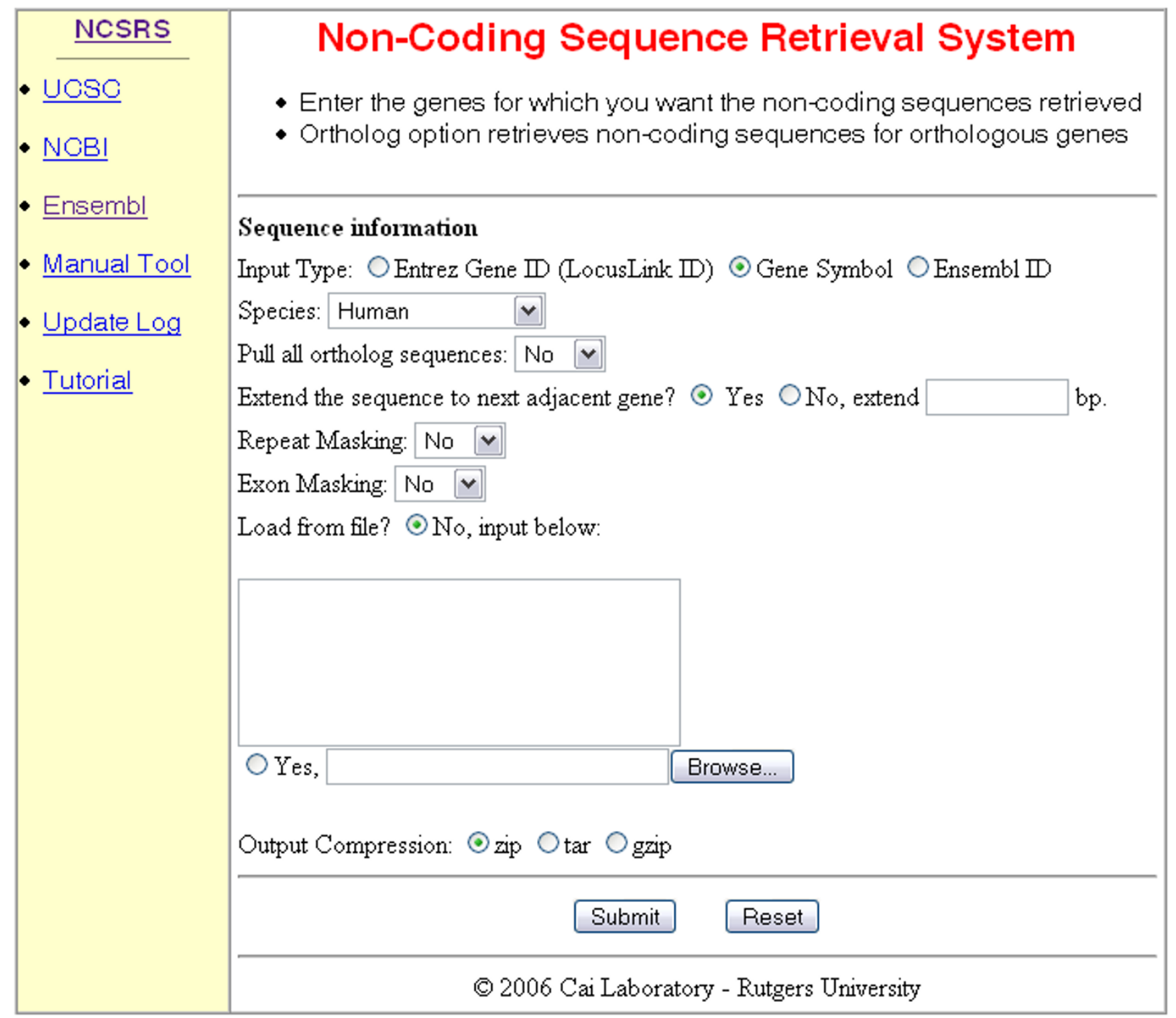

\section{Figure I}

Snapshot of the web based user interface for the NCSRS. The user interface allows the user to input the HUGO (Human Genome Organization) ID, i.e., Entrez gene ID (LocusLink ID), Gene Symbol, and Ensembl ID numbers and set the other search options.

approach, the user can obtain the sequences for multiple species by simply selecting the "pull all orthologs" option. Once the sequences are returned, a multiple sequence analysis can be performed for each set of homologous gene sequences. The system's ability to return sequences from multiple genomes in one run greatly increases the efficiency and speed of the system. Furthermore, it has been shown that increasing the number of genomes used in alignment analysis increases the signal-to-noise ratio and, if specific genomes are selected carefully, increases the likelihood of correctly predicting functionality [1]. If microarray data is the basis for analysis, the system's ability to handle multiple genes in a single query allows for the user to input multiple genes with similar expression patterns at one time to return the desired sequences. It is even possible to combine the two approaches and obtain sequences for all homologous genes of a set of genes with similar expression profiles. This allows for the system to be utilized by those who seek to learn more about genome-wide networks through their analysis [39]. 


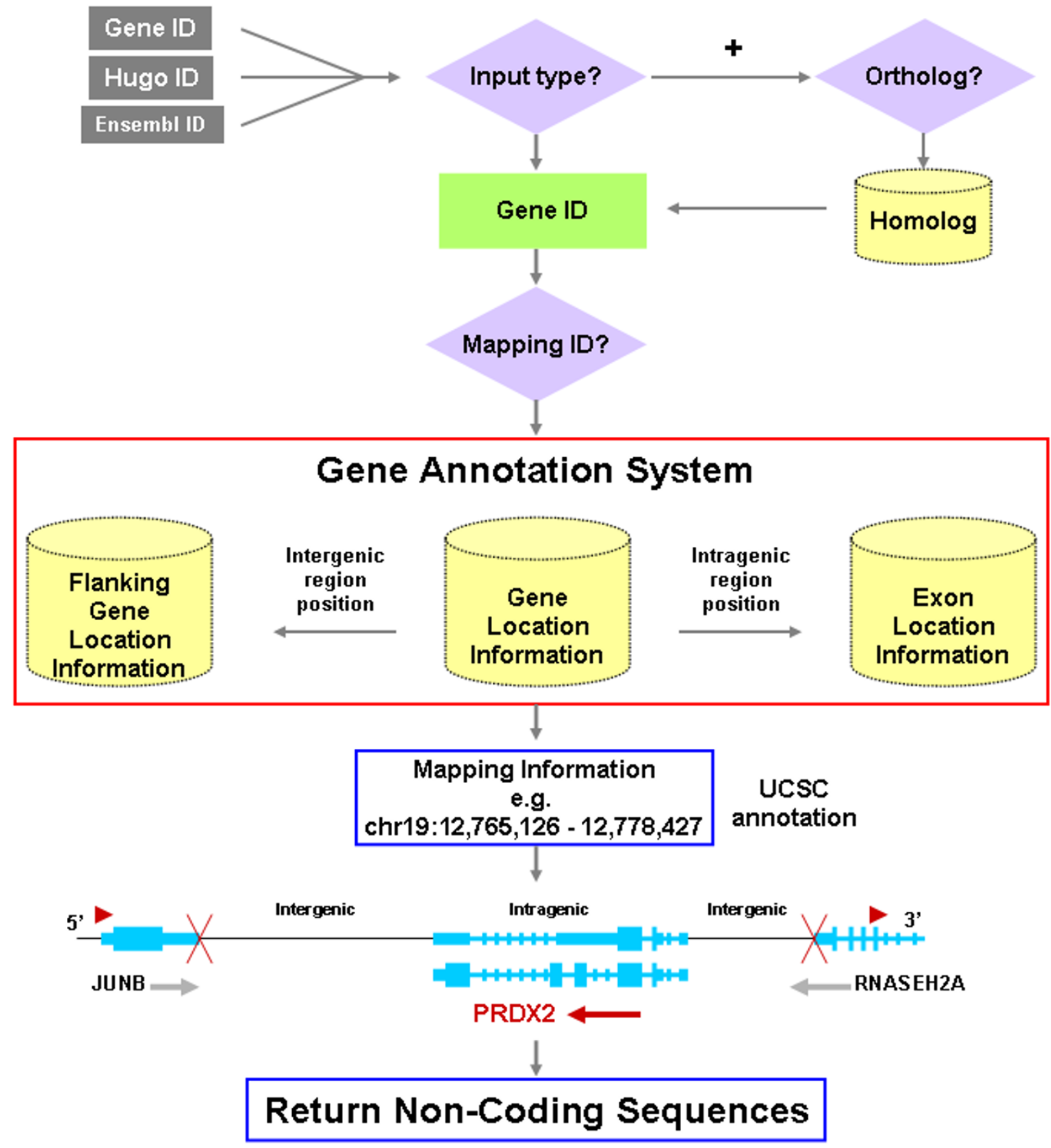

Figure 2

Work flow diagram of the NCSRS. The Refseq annotation uses Entrez gene IDs as the database key while Ensembl uses gene stable IDs. The input ID is converted into the appropriate database key if necessary. Entrez gene IDs are used directly for the Refseq annotation but are converted to gene stable IDs for the Ensembl annotation. Gene symbols are translated into Entrez gene IDs and gene stable IDs. Once the database keys are acquired, the homologous genes can be identified using the available homology databases if the "pull ortholog" option is activated. The database key is then used to access the mapping information that has been compiled from the annotation data. The mapping information is then used to locate the relevant sequences. These sequences are extracted then copied to a new ".fa" file with FASTA sequence format; and the annotation information about the exons is written to the ".exon" file. Thus, for each requested gene, there are one pair of files for each genome. 


\section{Non-Coding Sequence Retrieval System}

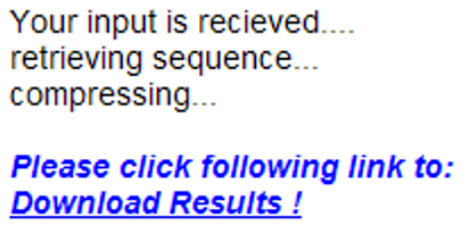

\begin{tabular}{|c|c|c|c|c|c|c|c|c|}
\hline human & chimpanzee & opossum & dog & cow & mouse & rat & chicken & zebrafish \\
\hline $\begin{array}{l}\text { OLIG2 } \\
e ! \text { w140 }\end{array}$ & $\begin{array}{l}\text { OLIG2 } \\
e !\end{array}$ & $\frac{\mathrm{OLIG} 2}{\mathrm{et}}$ & & $\frac{\mathrm{OLIG} 2}{\mathrm{et}}$ & $\begin{array}{l}\text { Olig2 } \\
e ! \text { wwat }\end{array}$ & 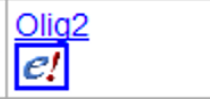 & & olig2 \\
\hline OTX2 & $\frac{O T \times 2}{E !}$ & $\frac{\mathrm{OTX} 2}{\mathrm{E} \text { ! }}$ & $\frac{\mathrm{OTX} 2}{\mathrm{Ee}}$ & $\frac{\text { OTX2 }}{\text { e! }}$ & $\frac{\text { Otx2 }}{e ! \text { wm: }}$ & $\frac{\text { OTX2_RAT }}{\mid \text { e! }}$ & $\frac{\text { OTX2 }}{\text { whin }}$ & $\frac{\mathrm{otx} 2}{\mathrm{et}}$ \\
\hline 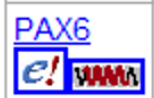 & $\frac{\mathrm{PAX6}}{\mathrm{E} \text { ! }}$ & $\frac{\text { PAX6 }}{\text { e! }}$ & $\frac{\text { PAX6 }}{\text { e! }}$ & $\frac{\mathrm{Q} 7 \mathrm{M} 308 \text { BOVIN }}{\text { e! }}$ & 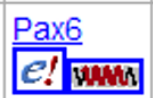 & $\frac{\text { PAX6_RAT }}{\text { e! mat }}$ & 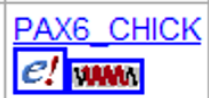 & pax6a \\
\hline $\begin{array}{l}\text { ROM1 } \\
e ! \text { wim: }\end{array}$ & $\frac{\mathrm{ROM} 1}{\mathrm{e} \text { e! }}$ & $\frac{\mathrm{ROM} 1}{\mathrm{et}}$ & $\frac{\mathrm{ROM} 1}{\mathrm{e} \text { e! }}$ & $\begin{array}{l}\text { ROM1_BOVIN } \\
\text { ef }\end{array}$ & $\frac{\text { Rom1 }}{\text { Ee! wima }}$ & 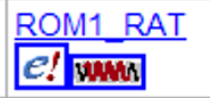 & & $\begin{array}{l}\text { zac: } 73336 \\
\text { et }\end{array}$ \\
\hline 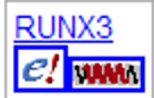 & $\frac{\text { RUNX3 }}{\text { ef! }}$ & $\frac{\text { RUNX3 }}{\text { ee! }}$ & $\frac{\text { Q5XTY6_CANFA }}{\text { e! }}$ & $\frac{\text { RUNX3 }}{\text { Ee! }}$ & 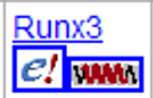 & $\frac{\mathrm{NP} 569109.1}{\mathrm{e} ! \mathrm{Wm}}$ & & $\frac{\text { runx } 3}{\text { e! }}$ \\
\hline
\end{tabular}

Figure 3

An example webpage that display the results for the NCSRS. The sequences and annotation information written to the FA and EXON files respectively are bundled and zipped into a single file that can be accessed by the "Download Results!" link. A table with links to NCBI, UCSC genome browser and Ensembl for the gene and specific species is also provided.

\section{Conclusion}

NCSRS combines a number of available genomic resources (a total of over $85 \mathrm{~Gb}$ sequences) and applies them to the specific task of identifying and retrieving noncoding sequences in an up to date web based application that is easy to use and requires no maintenance by the user. The unique features of this tool will be very helpful for those studying gene regulatory elements that exist in non-coding regions. Future work will include incorporating NCSRS with a program that analyzes non-coding sequences using a multi-sequence alignment algorithm and identifies highly conserved regions [10-15]. This pipeline will be designed to be able to rank potential gene regulatory elements according to the likelihood of functionality using sequence motif information of known transcription binding factors [40]. Ultimately the seamless integration of these two tools with the NCSRS will be implemented into a gene regulatory element finder pipeline. This will allow future experimental work and resources to focus on the verification of potential regulatory elements to those conserved elements that have a theoretically basis for regulatory function and therefore increase overall efficiency. The proposed pipeline will serve as the initial selection process for targeting experimental verification.

\section{Availability and requirements}

Project name: NCSRS

Project home page: http://cell.rutgers.edu/ncsrs/

Operating system(s): Platform independent

Programming language: Perl, PHP

Licence: GPL

Any restrictions to use by non-academics: None

\section{Authors' contributions}

LC identified the need to develop such a system, initiated the project, and designed the basic functions. SD and YZ wrote the source code for the software and web interface and contributed with ideas on overall design, feature requirements, and implementation. All authors participated in the drafting of the manuscript and approved the final version.

\section{Acknowledgements}

We wish to thank the many "NCSRS" users for their constructive comments. This work was supported in part by the Charles and Johanna Busch Fund. 


\section{References}

I. Frazer KA, Elnitski L, Church DM, Dubchak I, Hardison RC: Crossspecies sequence comparisons: a review of methods and available resources. Genome Res 2003, I3(I): I- I2.

2. Makalowski $W$ : The human genome structure and organization. Acta Biochim Pol 200 I, 48(3):587-598.

3. Consortium TENCODEP: The ENCODE (ENCyclopedia Of DNA Elements) Project. Science 2004, 306:636-640.

4. Nobrega MA, Ovcharenko I, Afzal V, Rubin EM: Scanning human gene deserts for long-range enhancers. Science 2003, 302(5644): 413.

5. Woolfe A, Goodson M, Goode DK, Snell P, McEwen GK, Vavouri T, Smith SF, North P, Callaway H, Kelly K, Walter K, Abnizova I, Gilks W, Edwards YJ, Cooke JE, Elgar G: Highly conserved non-coding sequences are associated with vertebrate development. PLoS Biol 2005, 3(I):e7.

6. Kellis M, Patterson N, Endrizzi M, Birren B, Lander ES: Sequencing and comparison of yeast species to identify genes and regulatory elements. Nature 2003, 423(6937):24I-254.

7. Lander ES, Linton LM, Birren B, Nusbaum C, Zody MC, Baldwin J, Devon K, Dewar K, Doyle M, FitzHugh W, Funke R, Gage D, Harris K, Heaford A, Howland J, Kann L, Lehoczky J, LeVine R, McEwan P, McKernan K, Meldrim J, Mesirov JP, Miranda C, Morris W, Naylor J, Raymond C, Rosetti M, Santos R, Sheridan A, Sougnez C, StangeThomann N, Stojanovic N, Subramanian A, Wyman D, Rogers J, Sulston J, Ainscough R, Beck S, Bentley D, Burton J, Clee C, Carter N, Coulson A, Deadman R, Deloukas P, Dunham A, Dunham I, Durbin R, French L, Grafham D, Gregory S, Hubbard T, Humphray S, Hunt A, Jones M, Lloyd C, McMurray A, Matthews L, Mercer S, Milne S, Mullikin JC, Mungall A, Plumb R, Ross M, Shownkeen R, Sims S, Waterston RH, Wilson RK, Hillier LW, McPherson JD, Marra MA, Mardis ER, Fulton LA, Chinwalla AT, Pepin KH, Gish WR, Chissoe SL, WendI MC, Delehaunty KD, Miner TL, Delehaunty A, Kramer JB, Cook LL, Fulton RS, Johnson DL, Minx PJ, Clifton SW, Hawkins T, Branscomb E, Predki P, Richardson P, Wenning S, Slezak T, Doggett $\mathrm{N}$, Cheng JF, Olsen A, Lucas S, Elkin C, Uberbacher E, Frazier M, Gibbs RA, Muzny DM, Scherer SE, Bouck JB, Sodergren EJ, Worley KC, Rives CM, Gorrell JH, Metzker ML, Naylor SL, Kucherlapati RS, Nelson DL, Weinstock GM, Sakaki Y, Fujiyama A, Hattori M, Yada T, Toyoda A, Itoh T, Kawagoe C, Watanabe H, Totoki Y, Taylor T, Weissenbach J, Heilig R, Saurin W, Artiguenave F, Brottier P, Bruls T, Pelletier E, Robert C, Wincker P, Smith DR, Doucette-Stamm L, Rubenfield M, Weinstock K, Lee HM, Dubois J, Rosenthal A, Platzer M, Nyakatura G, Taudien S, Rump A, Yang H, Yu J, Wang J, Huang G, Gu J, Hood L, Rowen L, Madan A, Qin S, Davis RW, Federspiel NA, Abola AP, Proctor MJ, Myers RM, Schmutz J, Dickson M, Grimwood J, Cox DR, Olson MV, Kaul R, Raymond C, Shimizu N, Kawasaki K, Minoshima S, Evans GA, Athanasiou M, Schultz R, Roe BA, Chen F, Pan H, Ramser J, Lehrach $H$, Reinhardt R, McCombie WR, de la Bastide M, Dedhia N, Blocker H, Hornischer K, Nordsiek G, Agarwala R, Aravind L, Bailey JA, Bateman A, Batzoglou S, Birney E, Bork P, Brown DG, Burge CB, Cerutti L, Chen HC, Church D, Clamp M, Copley RR, Doerks T, Eddy SR, Eichler EE, Furey TS, Galagan J, Gilbert JG, Harmon C, Hayashizaki Y, Haussler D, Hermjakob $H$, Hokamp K, Jang W, Johnson LS, Jones TA, Kasif S, Kaspryzk A, Kennedy S, Kent WJ, Kitts P, Koonin EV, Korf I, Kulp D, Lancet D, Lowe TM, McLysaght A, Mikkelsen T, Moran JV, Mulder N, Pollara V], Ponting CP, Schuler G, Schultz J, Slater G, Smit AF, Stupka E, Szustakowski J, Thierry-Mieg D, Thierry-Mieg J, Wagner L, Wallis J, Wheeler R, Williams A, Wolf YI, Wolfe KH, Yang SP, Yeh RF, Collins F, Guyer MS, Peterson J, Felsenfeld A, Wetterstrand KA, Patrinos A, Morgan MJ, de Jong P, Catanese JJ, Osoegawa K, Shizuya H, Choi S, Chen Y): Initial sequencing and analysis of the human genome. Nature 2001, 409(6822):860-921.

8. Bucher P: Regulatory elements and expression profiles. Curr Opin Struct Biol 1999, 9(3):400-407.

9. Roth FP, Hughes JD, Estep PW, Church GM: Finding DNA regulatory motifs within unaligned noncoding sequences clustered by whole-genome mRNA quantitation. Nat Biotechnol 1998, I 6( I 0):939-945.

10. Bejerano G, Pheasant M, Makunin I, Stephen S, Kent WJ, Mattick JS, Haussler D: Ultraconserved elements in the human genome. Science 2004, 304(5675): | 32 | - | 325.

II. Brudno M, Do CB, Cooper GM, Kim MF, Davydov E, Green ED, Sidow A, Batzoglou S: LAGAN and Multi-LAGAN: efficient tools for large-scale multiple alignment of genomic DNA. Genome Res 2003, I3(4):72I-73I.

12. Frazer KA, Pachter L, Poliakov A, Rubin EM, Dubchak I: VISTA: computational tools for comparative genomics. Nucleic Acids Res 2004, 32(Web Server issue):W273-9.

13. Mayor C, Brudno M, Schwartz JR, Poliakov A, Rubin EM, Frazer KA, Pachter LS, Dubchak I: VISTA : visualizing global DNA sequence alignments of arbitrary length. Bioinformatics 2000, I 6( I I): I046-1047.

14. Schwartz S, Kent WJ, Smit A, Zhang Z, Baertsch R, Hardison RC, Haussler D, Miller W: Human-mouse alignments with BLASTZ. Genome Res 2003, I3(I): 103-107.

15. Stojanovic N, Florea L, Riemer C, Gumucio D, Slightom J, Goodman M, Miller W, Hardison R: Comparison of five methods for finding conserved sequences in multiple alingments of gene regulatory regions. Nucleic Acids Res 1999, 27(19):3899-3910.

16. Schwartz S, Elnitski L, Li M, Weirauch M, Riemer C, Smit A, Green ED, Hardison RC, Miller W: MultiPipMaker and supporting tools: Alignments and analysis of multiple genomic DNA sequences. Nucleic Acids Res 2003, 3 I ( I 3):35 I 8-3524.

17. Schwartz S, Zhang Z, Frazer KA, Smit A, Riemer C, Bouck J, Gibbs R, Hardison R, Miller W: PipMaker--a web server for aligning two genomic DNA sequences. Genome Res 2000, I 0(4):577-586.

18. Levy S, Hannenhalli S, Workman C: Enrichment of regulatory signals in conserved non-coding genomic sequence. Bioinformatics 200I, I 7( I 0):87|-877.

19. Xie X, Lu J, Kulbokas EJ, Golub TR, Mootha V, Lindblad-Toh K, Lander ES, Kellis M: Systematic discovery of regulatory motifs in human promoters and 3' UTRs by comparison of several mammals. Nature 2005, 434(703I):338-345.

20. Bergman CM, Kreitman M: Analysis of conserved noncoding DNA in Drosophila reveals similar constraints in intergenic and intronic sequences. Genome Res 200I, I I(8): I 335-I345.

2I. Cliften PF, Hillier LW, Fulton L, Graves T, Miner T, Gish WR, Waterston RH, Johnston M: Surveying Saccharomyces genomes to identify functional elements by comparative DNA sequence analysis. Genome Res 200 I, I I(7): I I75-I I86.

22. Kellis M, Birren BW, Lander ES: Proof and evolutionary analysis of ancient genome duplication in the yeast Saccharomyces cerevisiae. Nature 2004, 428(6983):617-624.

23. Loots GG, Locksley RM, Blankespoor CM, Wang ZE, Miller W, Rubin $E M$, Frazer $K A$ : Identification of a coordinate regulator of interleukins 4,13 , and 5 by cross-species sequence comparisons. Science 2000, 288(5463): | 36-I40.

24. Thacker C, Marra MA, Jones A, Baillie DL, Rose AM: Functional genomics in Caenorhabditis elegans: An approach involving comparisons of sequences from related nematodes. Genome Res 1999, 9(4):348-359.

25. Boffelli D, McAuliffe J, Ovcharenko D, Lewis KD, Ovcharenko I, Pachter L, Rubin EM: Phylogenetic shadowing of primate sequences to find functional regions of the human genome. Science 2003, 299(56 I I): I39|- I394.

26. Dubchak I, Brudno M, Loots GG, Pachter L, Mayor C, Rubin EM, Frazer KA: Active conservation of noncoding sequences revealed by three-way species comparisons. Genome Res 2000, I 0(9): | 304-1306.

27. Lazzarato F, Franceschinis G, Botta M, Cordero F, Calogero RA: RRE: a tool for the extraction of non-coding regions surrounding annotated genes from genomic datasets. Bioinformatics 2004, 20( I 6):2848-2850.

28. Pruitt KD, Maglott DR: RefSeq and LocusLink: NCBI gene-centered resources. Nucleic Acids Res 200I, 29(I): I37-I40.

29. Curwen V, Eyras E, Clarke L, Mongin E, Searle SMJ, Clamp M: The Ensembl automatic gene annotation system. Genome Res 2004, I 4(5):942-950.

30. Kent WJ, Sugnet CW, Furey TS, Roskim KM, Pringle TH, Zahler AM, Haussler D: The Human Genome Browser at UCSC. Genome Res 2002, I 2(6):996-1006.

31. UCSC FTP [ftp://hgdownload.cse.ucsc.edu/goldenPath/]

32. Ensembl FTP [ftp://ftp.ensembl.org/pub/current mart/]

33. Hubbard TJP, Aken BL, Beal K, Ballester B, Caccamo M, Chen Y, Clarke L, Coates G, Cunningham F, Cutts T, Down T, Dyer SC, Fitzgerald S, Fernandez-Bane J, Graf S, Haide S, Hammond M, Herrero J, Holland R, Howe K, Howe K, Johnson N, Kahari A, Keefe D, Kokocinski F, Kulesha E, Lawson D, Longden I, Melsopp C, Megy K, MeidI P, Overduin B, Parker A, Prlic A, Rice S, Rios D, Schuster M, Sealy I, Sev- 
erin J, Slater G, Smedley D, Spudich G, Trevanion S, Vilella A, Vogel J, White S, Wood M, Cox T, Curwen V, Durbin R, Fernandez-Suarez XM, Flicek P, Kasprzyk A, Proctor G, Searle S, Smith J, Ureta-Vidal A, Birney E: Ensembl 2007. Nucleic Acids Research 2006, 00(Database issue):DI-D8.

34. Homologene [http://www.ncbi.nlm.nih.gov/entrez/ query.fcgi?d $b=$ homologene]

35. Homologene FTP [ftp://ftp.ncbi.nih.gov/pub/HomoloGene/cur rent]

36. Entrez Gene [http://www.ncbi.nlm.nih.gov/entrez/ query.fcgi?db=gene]

37. UCSC Genome Browser [http://genome.ucsc.edu/]

38. Ensembl [http://www.ensembl.org/]

39. Myers CL, Robson D, Wible A, Hibbs MA, Chiriac C, Thessfeld CL, Dolinski K, Troyanskaya OG: Discovery of biological networks from diverse functional genomic data. Genome Biol 2005, 16(I3): RII4.

40. Hallikas O, Palin K, Sinjushina N, Rautiainen R, Partanen J, Ukkonen E, Taipale J: Genome-wide prediction of mammalian enhancers based on analysis of transcription-factor binding affinity. Cell 2006, I 24(I):47-59.

Publish with Bio Med Central and every scientist can read your work free of charge

"BioMed Central will be the most significant development for disseminating the results of biomedical research in our lifetime. "

Sir Paul Nurse, Cancer Research UK

Your research papers will be:

- available free of charge to the entire biomedical community

- peer reviewed and published immediately upon acceptance

- cited in PubMed and archived on PubMed Central

- yours - you keep the copyright

Submit your manuscript here:

http://www.biomedcentral.com/info/publishing_adv.asp
BioMedcentral 